\title{
Statistical Optimization of Blanching Time and Temperature of Irish York Cabbage Using Desirability Function
}

Amit Jaiswal

Technological University Dublin, amit.jaiswal@tudublin.ie

Nissreen Abu-Ghannam

Technological University Dublin, nissreen.abughannam@tudublin.ie

Shilpi Gupta

Technological University Dublin, shilpi.19may@gmail.com

Follow this and additional works at: https://arrow.tudublin.ie/schfsehart

Part of the Food Chemistry Commons, and the Food Processing Commons

\section{Recommended Citation}

Gupta, S., Jaiswal, A.K. \& Nissreen Abu-Ghannam (2012). Statistical optimization of blanching time and temperature of Irish York Cabbage using desirability function. Journal of Food Processing \& Preservation, doi:10.1111/j.1745-4549.2011.00574.x

This Article is brought to you for free and open access by the School of Food Science and Environmental Health at ARROW@TU Dublin. It has been accepted for inclusion in Articles by an authorized administrator of ARROW@TU Dublin. For more information, please contact arrow.admin@tudublin.ie, aisling.coyne@tudublin.ie, gerard.connolly@tudublin.ie.

Funder: Irish Government under the Technological Sector Research Scheme (Strand III) of the National Development Plan 


\title{
STATISTICAL OPTIMIZATION OF BLANCHING TIME AND TEMPERATURE OF IRISH YORK CABBAGE USING DESIRABILITY FUNCTION
}

\author{
SHILPI GUPTA, AMIT K. JAISWAL and NISSREEN ABU-GHANNAM ${ }^{1}$ \\ School of Food Science and Environmental Health, College of Sciences and Health, Dublin Institute of Technology, Cathal Brugha Street, Dublin 1, \\ Ireland
}

\author{
${ }^{1}$ Corresponding author. TEL: 353-1-402-7570; \\ FAX: 353-1-878-8978; EMAIL: \\ nissreen.abughannam@dit.ie
}

Received for Publication January 19, 2011 Accepted for Publication June 21, 2011

doi:10.1111/j.1745-4549.2011.00574.x

\begin{abstract}
The effect of different heat treatments, as a means of preprocessing, on the phytochemicals present in Irish York cabbage was studied. A comparison of blanching (by immersing in water) and microwaving (using water as a medium) indicated that microwaving is detrimental to the phytochemicals present in cabbage. To achieve a blanching time and temperature combination that would result in minimal loss of phytochemicals, central composite design that integrates a desirability approach was used. A second-order polynomial equation was developed, indicating the effect of the blanching time and temperature on the total phenol content (TPC), total flavonoid content (TFC) and 2,2-diphenyl-1-picrylhydrazyl (DPPH) values. Contour maps generated using the response surface equation showed that the experimental variables significantly affected the response. The optimized factors ( $85 \mathrm{C}$ and $2 \mathrm{~min}$ ) were used for blanching York cabbage to obtain a TPC, TFC and half maximal effective concentration for DPPH of $31.01 \mathrm{mg}$ gallic acid equivalents/g, $21.2 \mathrm{mg}$ quercetin equivalents/g and $0.93 \mathrm{mg} / \mathrm{mL}$, respectively.
\end{abstract}

\section{PRACTICAL APPLICATIONS}

Processing of cabbage is generally carried out before it can be developed into a product. The present study used statistical software to obtain the time and temperature conditions for preprocessing of cabbage. The statistical software helped in achieving conditions wherein minimal loss of phytochemicals took place. The application of the software for optimizing the conditions helped in cutting down the amount of time and resources for identifying optimum value of different factors.

\section{INTRODUCTION}

Cabbage (Brassica oleracea Capitata) is a leafy garden plant and is among the most important vegetables consumed worldwide due to its availability in local markets and consumer preference (Kusznierewicz et al.2008). It belongs to the family of Brassicaceae (or Cruciferae) along with collards, brussels sprouts, broccoli, cauliflower and kale. According to the data from the Food and Agriculture Organization of the

3 United Nations (2011) (FAO, http://www.fao.org), the production capacity of Brassicaceae in Ireland was around 45,000 metric tons for the year 2008. Cabbage is rich in phytochemicals such as flavonoids and glucosinolates and their hydrolysis products, and is a good source of healthpromoting compounds that show preventive effect against cancer, atherosclerosis, nephritis and diabetes mellitus (Taveira et al. 2009). Flavonoids and phenolic acids are the most characterized groups of phenolic compounds in Brassica. Flavonoids protect plants against UV radiation, microorganisms and plant-feeding animals. They can act in vitro as scavengers of active oxygen species and electrophiles and as chelators of metal ions, and thus may be beneficial in vivo to reduce the risk of cardiovascular diseases (Hollman 2001). A number of flavonoids have been identified in cabbage, including myricetin, quercetin, kaempferol, luteolin, delphinidin, cyanidin and pelargonidin (Chu et al. 2000; Franke et al. 
2004). Phenolic acids, such as benzoic, hydroxybenzoic, vanillic and caffeic, have antimicrobial and antifungal properties. Hydroxycinnamic acid derivatives, such as caffeic, chlorogenic, sinapic, ferulic and $p$-coumaric acids, possess strong antioxidant activity because of the inhibition of lipid oxidation and scavenging reactive oxygen species (Sroka and Cisowski 2003). Indole-3-carbinole, sulforaphane and indole from cabbage help in stabilizing the body's antioxidant and detoxification mechanisms that eradicate cancer-producing substances (Brooks et al. 2001).

Heat applications are a common practice in the processing of food products in household or in industries in order to render them palatable and microbiologically safe. Typical applications include using heat treatments such as blanching or microwaving. As cabbage would need to undergo some heat treatment prior to usage, it was relevant to assess the effects of heat treatment on the stability of the phytochemicals present in it. Processing can result in reduction of constituents by leaching or due to thermal destruction (Rungapamestry et al. 2006). The processing methods might liberate the natural bioactive compounds (Duh et al. 2001; Lombard et al. 2005; Turkmen et al. 2005) or might reduce (Ismail et al. 2004) them in comparison with fresh foods. The degree to which phytochemicals change during processing depends on their sensitivity to modifications or degradations and length of exposure to a processing technique (Breena 1994). Puupponen-Pimiä et al. (2003) found that blanching reduced the antioxidant capacity by $23 \%$ for cauliflower, but increased it by $9 \%$ for cabbage. Wu et al. (2004) found a reduction of $14 \%$ in oxygen radical absorbance capacity values for cooked broccoli and an increase of $41 \%$ for cooked red cabbage. Ismail et al. (2004) found that thermal treatment decreased the total phenolic content (TPC) in all vegetables such as kale, spinach, cabbage, swamp cabbage and shallots. The evaluation of the influence of food processing is a key factor while establishing technological conditions that enable one to preserve or improve the original activity and bioavailability of naturally occurring compounds in foods (Kusznierewicz et al. 2008). Thus, it is important to optimize the processing conditions such that the processed product still retains its health-promoting properties. Proper combination of time and temperature during processing methods such as blanching or microwaving is important in order to minimize quality loss during processing. These methods might cause undesirable changes on the physicochemical properties, such as color, texture or bioactive compounds, on account of heat-induced diffusion or leaching losses. Thus, it is important to optimize the time and temperature of any processing method in order to achieve minimal loss of quality. The "one-at-a-time-approach" can be used to optimize the processing time and temperature in order to obtain conditions that would result in minimal loss of the bioactive compounds. However, this method is extremely time- consuming and disregards the complex interactions among various physicochemical parameters (Abdel-Fattah et al. 2005). Response surface methodology (RSM) is a collection of mathematical and statistical techniques for searching optimum conditions of factors for desirable responses and evaluating the relative significance of several affecting factors even in the presence of complex interactions. The design leads to the generation of contour plots by linear or quadratic effects of the key variables, and a model equation is derived that fits the experimental data to calculate the optimal response of the system.

This work is part of an ongoing project to evaluate the potential of Irish York cabbage as a substrate for the development of a fermented product. However, before fermentation, it is important to process the raw material in order to render them free from of contaminating microflora and to make them slightly palatable. At the same time, the processed product should still retain its health-promoting properties. Hence, in the present study, processing was tried with microwaving and blanching. Thereafter, RSM was used to optimize the time and temperature of blanching to obtain conditions that would result in minimal loss of phytochemicals as compared with the raw cabbage. A desirability function was used to simultaneously optimize the responses and to locate the optimal values for the blanching conditions.

\section{MATERIALS AND METHODS}

\section{Chemicals}

Folin-Ciocalteu phenol reagent, 2,2-diphenyl-1picrylhydrazyl (DPPH), gallic acid, sodium carbonate, aluminum chloride, sodium nitrate and quercetin were purchased from Sigma-Aldrich Chemical Co. (Steinheim, Germany). All other chemicals used were of analytical grade.

\section{Plant Material}

Fresh Irish York cabbage was purchased from a local supermarket in Dublin in December 2009. Immediate outer leaves that get spoiled during transportation were discarded and the layers of leaves after that were chopped into $0.5 \times 5$ - to 6 -cm pieces using a vegetable cutting machine.

\section{Processing Treatments}

Blanching Treatment. Blanching was carried out by immersing cabbage in hot water in a wire mesh basket (cylindrical; $10 \mathrm{~cm}$ in diameter and $15 \mathrm{~cm}$ in height). The basket containing $50 \mathrm{~g}$ cut cabbage was immersed in a thermostatically controlled water bath $( \pm 0.5 \mathrm{C})$ containing $5 \mathrm{~L}$ of water. For preliminary experiments, blanching was carried out at 80 and $100 \mathrm{C}$ for 4,8 and $12 \mathrm{~min}$. The blanching time was 
TABLE 1. LEVEL AND CODE OF INDEPENDENT VARIABLES, TIME AND TEMPERATURE USED FOR CENTRAL COMPOSITE EXPERIMENTAL DESIGN

\begin{tabular}{|c|c|c|c|c|c|c|}
\hline \multirow{2}{*}{$\begin{array}{l}\text { Independent } \\
\text { variables }\end{array}$} & \multirow{2}{*}{$\begin{array}{l}\text { Coded } \\
\text { symbols }\end{array}$} & \multicolumn{5}{|l|}{ Levels } \\
\hline & & -2 & -1 & 0 & +1 & +2 \\
\hline Temperature (C) & $x_{1}$ & 83 & 85 & 90 & 95 & 97 \\
\hline Time (min) & $x_{2}$ & 0.34 & 2 & 6 & 10 & 12 \\
\hline
\end{tabular}

measured as soon as the vegetables were placed inside the water at respective temperatures. The blanched material was drained, cooled in ice water $(1-4 \mathrm{C})$ for $1 \mathrm{~min}$ and then allowed to drain for $30 \mathrm{~s}$.

Microwave Treatment. Microwave heating using water as a medium was carried out in a domestic microwave (Sharp,

5 model R 244; Sharp Electronics, U.K.) with a maximum output power of $800 \mathrm{~W}$. A $50 \mathrm{~g}$ cabbage sample prepared as described in the Plant Material section was placed in a $500-\mathrm{mL}$ beaker filled with $100 \mathrm{~mL}$ of deionized water. These were then placed inside the microwave oven at 400 and $800 \mathrm{~W}$ for 4, 8 and $12 \mathrm{~min}$. The microwaving time was noted as soon as the vegetables were placed inside the microwave at the respective power $(\mathrm{W})$. The microwaved material was drained, cooled in ice water $(1-4 \mathrm{C})$ for $1 \mathrm{~min}$ and then allowed to drain for $30 \mathrm{~s}$.

\section{Experimental Design and Evaluation}

RSM was applied to optimize the blanching time and temperature (Table 1) for achieving conditions that result in minimal loss of the phytochemicals present in cabbage (Table 1) using Design Expert (version 5.0.9) software (Stat-

6 Ease Corporation, Minneapolis, MN). A $2^{n}$ factorial central composite design (CCD) with two factors and five levels, including five replicates at the center point, was used for fitting a second-order response surface. CCD coupled with a polynomial model is a very powerful combination that usually provides an adequate representation of most continuous response surfaces over a relatively broad factor domain. CCD uses the method of least squares regression to fit the data to a quadratic model. The quadratic model for each response was as follows:

$$
Y=\beta_{0}+\sum \beta_{i} X_{i}+\sum \beta_{i i} X_{i}^{2}+\sum \sum \beta_{i j} X_{i} X_{j}
$$

where $Y$ is the predicted response, $\beta_{0}$ is a constant, $\beta_{i}$ is the linear coefficient, $\beta_{i i}$ is the quadratic coefficient, $\beta_{i j}$ is the interaction coefficient of variables $i$ and $j$, and $X_{i}$ and $X_{j}$ are independent variables. The software uses this quadratic model to build the response surfaces. The adequacy of the model was determined by evaluating the lack of fit, coefficient of determination $\left(R^{2}\right)$ and the Fisher test value ( $F$ value) obtained from the analysis of variance (ANOVA) that was generated by the software. Statistical significance of the model and model parameters were determined at the $5 \%$ probability level $(\alpha=0.05)$. Three-dimensional response surface plots and contour plots were generated by keeping one response variable at its optimal level and plotting that against two factors (independent variables). The independent variables selected are shown in Table 1 along with their low, medium and high levels.

\section{Optimization of the Factors}

The multiresponse analysis of response surface design using desirability approach was used to optimize the blanching time and temperature. Multiresponse analysis involves first building an appropriate response surface model for each response and then trying to find a set of operating conditions that in some sense optimize all responses or at least keep them in the desired ranges. After fitting the models and residual analysis of all responses, the desirability function was used for optimization of these multiresponses simultaneously. The general approach is to first convert each response into an individual desirability function $d_{i}$ that varies for the range $0 \leq d_{i} \leq 1$, wherein if the response is at its goal or target, then $d_{i}=1$, and if the response is outside the acceptable region, then $d_{i}=0$. Then, the design variables are chosen to maximize the overall desirability:

$$
D=\left(d_{1} \times d_{2} \times d_{3} \times \ldots d_{n}\right)^{\frac{1}{n}}
$$

where $n$ is the number of responses.

\section{Preparation of Extracts}

The processed sample was submerged in liquid nitrogen and ground to a coarse powder using mortar and pestle. Crushed cabbage ( $5 \mathrm{~g}$ ) was extracted using $60 \%$ methanol with 1-min nitrogen flushing. Flasks were kept in a shaking incubator (Innova 42; Mason Technology, Dublin, Ireland) at $100 \mathrm{rpm}$ and $40 \mathrm{C}$ for $2 \mathrm{~h}$. The infusions were filtered and evaporated to dryness in a multi-evaporator (Syncore Polyvap; Mason Technology) and stored at $-20 \mathrm{C}$ until used. All extractions were carried out in triplicate.

\section{Phytochemical Analysis}

TPC. The amount of total phenolic compounds in the crude methanol extract was determined using the Folin-Ciocalteu phenol reagent (Taga et al. 1984). The absorbance of all sample solutions against the blank reagent was determined at $720 \mathrm{~nm}$ with a spectrophotometer (Genesys 20; Thermo 
TABLE 2. COMPARISON OF TOTAL PHENOL CONTENT AND TOTAL FLAVONOID CONTENT UNDER DIFFERENT MICROWAVING AND BLANCHING CONDITIONS

\begin{tabular}{|c|c|c|c|c|c|c|c|c|}
\hline \multirow{3}{*}{$\begin{array}{l}\text { Time } \\
\text { (min) }\end{array}$} & \multicolumn{4}{|c|}{ Microwave (W) } & \multicolumn{4}{|c|}{ Blanching (C) } \\
\hline & \multicolumn{2}{|l|}{ Total phenol* } & \multicolumn{2}{|c|}{ Total flavonoid $†$} & \multicolumn{2}{|c|}{ Total phenol* } & \multicolumn{2}{|c|}{ Total flavonoid $†$} \\
\hline & $400 \mathrm{~W}$ & $800 \mathrm{~W}$ & $400 \mathrm{~W}$ & $800 \mathrm{~W}$ & $80 \mathrm{C}$ & $100 \mathrm{C}$ & $80 \mathrm{C}$ & $100 \mathrm{C}$ \\
\hline 4 & $20.1 \pm 0.6^{\mathrm{a}}$ & $24.6 \pm 1.7^{\mathrm{a}}$ & $14.4 \pm 0.6^{\mathrm{a}}$ & $13.1 \pm 0.6^{\mathrm{a}}$ & $23.6 \pm 0.6$ & $23.6 \pm 0.2^{\mathrm{a}}$ & $17.9 \pm 1.9^{\mathrm{a}}$ & $16.7 \pm 0.7^{\mathrm{a}}$ \\
\hline 8 & $17.2 \pm 2.6^{a}$ & $21.7 \pm 0.4^{b}$ & $13.8 \pm 1.2^{\mathrm{a}}$ & $10.6 \pm 1.6^{b}$ & $24.9 \pm 0.9$ & $23.5 \pm 0.4^{a}$ & $17.5 \pm 1.2^{\mathrm{a}}$ & $19.2 \pm 1.9^{b c}$ \\
\hline 12 & $12.3 \pm 2.9^{b}$ & $15.8 \pm 1.3^{c}$ & $10 \pm 1.2^{b}$ & $7.5 \pm 1.2^{c}$ & $25.4 \pm 1.3$ & $33.9 \pm 0.4^{a}$ & $17.5 \pm 1.2^{\mathrm{a}}$ & $22.1 \pm 1.9^{c}$ \\
\hline
\end{tabular}

* mg GAE/gm dry extract.

† mg QE/gm dry extract.

a-c Means within a column are significantly different.

$\mathrm{GAE}$, gallic acid equivalents; $\mathrm{QE}$, quercetin equivalents

8 Spectronic, Madison, WI). The TPC of the cabbage was expressed as mg gallic acid equivalents (GAE)/g dry extract.

Total Flavonoid Content (TFC). The TFC was determined by a colorimetric method described by Liu et al. (2009). Briefly, $0.25 \mathrm{~mL}$ of extract from stock, $1.25 \mathrm{~mL}$ of deionized water and $0.075 \mathrm{~mL}$ of $\mathrm{NaNO} 2(5 \%)$ solution were mixed in a test tube. After $6 \mathrm{~min}, 0.15 \mathrm{~mL}$ of $10 \%$ solution of monohydrate $\mathrm{AlCl}_{3}$ was added and allowed to stand for another $5 \mathrm{~min}$. Finally, $0.5 \mathrm{~mL}$ of $\mathrm{NaOH}(1 \mathrm{M})$ was added and the volume of reaction mixture was made up to $2.5 \mathrm{~mL}$ and mixed well. The absorbance was recorded immediately at $510 \mathrm{~nm}$ using the spectrophotometer against the blank. TFC was expressed as mg quercetin equivalents $(\mathrm{QE}) / \mathrm{g}$ dry extract.

\section{Antioxidant Analysis}

DPPH Radical-Scavenging Assay. This assay was carried out as described by Yen and Chen (1995), with some modifications. Briefly, the assay was performed in a 96-well roundbottom microplate with 1:1 ratio of $100 \mu \mathrm{l}$ of DPPH radical solution $(165 \mu \mathrm{M})$ and $100 \mu \mathrm{l}$ of sample. Different concentrations were tested for each sample in order to get half maximal effective concentration $\left(\mathrm{EC}_{50}\right)$ value. The DPPH solution was freshly prepared for each experiment in methanol. The reaction mixtures were incubated for $30 \mathrm{~min}$ at $25 \mathrm{C}$ in dark conditions, and the absorbance was measured at $517 \mathrm{~nm}$ in a microplate reader (Powerwave; BioTek,

9 Winooski, VT). The ability to scavenge the DPPH radical was calculated using the following equation:

$$
\text { Scavenging capacity }(\%)=\left(1-\left[\frac{A_{\text {sample }}-A_{\text {sample blank }}}{A_{\text {control }}}\right]\right)
$$

where $A_{\text {control }}$ is the absorbance of the control (DPPH solution without sample), $A_{\text {sample }}$ is the absorbance of the test sample (DPPH solution plus test sample) and $A_{\text {sample blank }}$ is the absorbance of the sample only (sample without any DPPH solution). The calculated $\mathrm{EC}_{50}$ values indicate the concentration of sample required to scavenge $50 \% \mathrm{DPPH}$ radicals. The lower the $\mathrm{EC}_{50}$ value of the sample, the higher the antioxidant capacity.

\section{Statistical Analysis}

All experiments were carried out in triplicate and replicated at least twice. Results are expressed as mean \pm standard deviation. All statistical analyses were carried out using STATGRAPHICS Centurion XV. Statistical differences between extract activities were determined using ANOVA, followed by least significant difference testing. Differences were considered statistically significant when $P<0.05$.

\section{RESULTS AND DISCUSSION}

\section{Effect of Blanching and Microwaving on the Phytochemicals}

The values of total phenol and total flavonoid in fresh York cabbage were $33.5 \pm 0.7 \mathrm{mg} \mathrm{GAE} / \mathrm{g}$ dry extract and $21.6 \mathrm{mg}$ QE/g dry extract, respectively. TPC was higher than those reported in other studies (Volden et al. 2009a). The values were slightly lower than those reported for red cabbage (Volden et al.2008). The aim of the present study was to find out a preprocessing method that would result in a reduction in the loss of phytochemicals from cabbage. For this, a preliminary study was carried out wherein cabbage leaves were blanched and microwaved. Following heat treatment, the cabbage leaves were extracted with $60 \%$ methanol, and TPC and TFC of the extract were studied. In order to determine which heat treatment method will result in a lesser destruction of the phytochemicals as compared with raw cabbage, fresh cabbage was blanched ( 80 and 100C) and microwaved (400 and $800 \mathrm{~W}$ ) for 4, 8 and $12 \mathrm{~min}$. It was noted that both heat treatments resulted in a reduction in the TPC and TFC (Table 2), and microwave heating was found to be more destructive. ANOVA showed significant differences 
$(P<0.05)$ in the TPC and TFC between fresh and heat treated cabbage. Heat processing can induce significant changes in the phenolic content and it could be the result of processes such as thermal degradation (autoxidation or breakdown), diffusion or/and leaching (Lindley 1998; Amin et al. 2006). Microwaving at 400 and $800 \mathrm{~W}$ resulted in $40-63 \%$ and $26.5-$ $53 \%$ reduction in TPC, respectively. Blanching at $80 \mathrm{C}$ resulted in 24-29\% reduction in TPC. When the blanching was carried out at $100 \mathrm{C}$ for $4 \mathrm{~min}$, a reduction of $29 \%$ was seen, but heating for higher times resulted in almost equivalent TPC as compared with the control samples. Xu and Chang (2008) reported a loss of $40-50 \%$ in the phenolic content of green pea, yellow pea and chick pea due to leaching of phenolics into boiling water as compared with raw peas. Zhang and Hamauzu (2004) found a 72\% reduction in TPC in broccoli florets boiled for $5 \mathrm{~min}$ using a vegetable-to-water ratio of 1:20. This is much larger than the losses found in our study for both blanched (vegetable-to-water ratio of 1:100) and microwaved (vegetable-to-water ratio of 1:10) samples.

In the case of TFC, similar results were seen wherein microwaving resulted in a 33.5-65.9\% reduction in TFC for all the combinations studied. Blanching resulted in a reduction of $11-23 \%$ in TFC and almost similar TFC was obtained as compared with control when blanching was carried out at $80 \mathrm{C}$ for $12 \mathrm{~min}$. Thermal processing might have resulted in a loss of phytochemicals from the cabbage to the treatment water. The results showed microwaving to be more destructive of phytochemicals. Similar results have been found by other researchers. Ismail et al. (2004) found that thermal treatment decreased the TPC in all vegetables, such as kale, spinach, cabbage, swamp cabbage and shallots, and antioxidant activity in some of them. Puupponen-Pimiä et al. (2003) reported a $13 \%$ reduction in TPC upon blanching and $10-21 \%$ reduction was reported by Volden et al. (2009b). Sultana et al. (2008) reported that different cooking methods affect the antioxidant properties of vegetables, with microwave cooking showing the most deleterious effect than other methods. Cerretani et al. (2009) also reported a loss of phenolic content in olive oil after microwave heating.

However, in spite of all the reductions, blanching at $100 \mathrm{C}$ for 12 min resulted in 44 and $31 \%$ increase in TPC and TFC, respectively. Although the TPC and TFC were reduced as compared with raw cabbage, however, the content was found to increase as the blanching time was increased. Generally, phenolic compounds in fruits and vegetables are bonded to dietary fiber, proteins or to sugars in plants to form complex structures. It could be possible that higher temperature resulted in the breakdown of these complexes, thus increasing their extractability (Gawlik-Dziki 2008). Roy et al. (2009) also reported that an increase in phenolic and flavonoid content in broccoli due to heat could be a result of the disruption of cell wall and cell membranes, which ultimately release phytochemicals from the insoluble portions. As blanching resulted in better retention of phytochemicals than microwaving, optimization using RSM was applied to the blanching process with respect to time and temperature.

\section{Statistical Analysis of Results Obtained by Experimental Design}

The aim of this work was to focus on optimizing preprocessing conditions of cabbage in preparation for further product development. As cabbage is rich in many antioxidant compounds, it is important for the processed product to have bioactives comparable with those present in the raw vegetable. Time and temperature combination used for the processing of vegetables is very crucial if the aim is to optimize the concentration of bioactive compounds. To perform such work using conventional techniques such as the "onefactor-at-a-time" method is extremely laborious and timeconsuming; moreover, such methods do not guarantee the determination of optimal conditions and are unable to detect synergistic interactions, if any, between these two factors. Thus, RSM was used for the optimization of these parameters.

The 13 experiments proposed by the RSM with two factors and five levels (Table 3), including five replicates at the center point, were used for fitting a second-order response surface model. The five center point runs provided a measure of process stability and inherent variability. The variation in the bioactives under different conditions is shown in Table 3.

Effect of Process Variables on TPC. Experimental results for TPC were fitted to a full quadratic second-order polynomial equation by applying multiple regression analysis (Eq. 4), and the regression coefficients obtained to predict the polynomial model for TPC are as follows:

$$
\begin{gathered}
\mathrm{TPC}=25.47+0.53 X_{1}-1.27 X_{2}-0.81 X_{1}^{2} \\
+3.04 X_{2}^{2}+1.95 X_{1} X_{2}
\end{gathered}
$$

When the values of $X_{1}-X_{2}$ were substituted in the above equation, the predicted TPC $(Y)$ was obtained. A comparison of predicted and experimentally obtained values can be seen in Table 3.

In order to determine whether or not the quadratic model is significant in simulating the experimental results, ANOVA was conducted. The $P$ values were used as a tool to check the significance of each coefficient, which also indicated the interaction strength of each parameter. The smaller the $P$ values are, the higher the significance of the corresponding coefficient (Murthy et al. 2000). The corresponding $P$ values suggest that among the test variables used in this study, $\left(X_{2}\right)^{2}$ (time $\times$ time) is a significant model term with $P$ values of less than 0.05 (Table 4). Thus, time is the major limiting factor for TPC and a small variation can alter the content. The goodness 


\begin{tabular}{|c|c|c|c|c|c|c|c|}
\hline \multirow[b]{2}{*}{ Temp (C) } & \multirow[b]{2}{*}{ Time $(\min )$} & \multicolumn{2}{|c|}{ TPC (mg GAE/g [DE]) } & \multicolumn{2}{|c|}{$\operatorname{TFC}(\mathrm{mg}$ QE/g [DE]) } & \multicolumn{2}{|c|}{ DPPH $(\mathrm{mg} / \mathrm{mL})$} \\
\hline & & $\operatorname{Exp}^{a}$ & Pred $^{\mathrm{b}}$ & $\operatorname{Exp}^{a}$ & Pred $^{b}$ & $\operatorname{Exp}^{a}$ & Pred $^{b}$ \\
\hline 90 & 6 & 27 & 25.47 & 16.04 & 15.53 & 1.1 & 1.15 \\
\hline 90 & 0.34 & 33.48 & 33.34 & 20.21 & 20.7 & 0.90 & 0.94 \\
\hline 83 & 6 & 24.2 & 23.11 & 17.6 & 17.6 & 1.06 & 1.13 \\
\hline 90 & 6 & 24.7 & 25.47 & 15 & 15.53 & 1.12 & 1.29 \\
\hline 85 & 10 & 25.07 & 24.85 & 18.33 & 18.17 & 1.33 & 12.9 \\
\hline 97 & 6 & 21.74 & 24.6 & 16.46 & 17.47 & 1.08 & 1.02 \\
\hline 85 & 2 & 28.26 & 29.49 & 20.42 & 20.28 & 0.98 & 0.91 \\
\hline 90 & 6 & 25.65 & 25.47 & 15 & 15.53 & 1.18 & 1.15 \\
\hline 90 & 6 & 24 & 25.47 & 15.62 & 15.53 & 1,240 & 1.15 \\
\hline 95 & 2 & 30 & 28.45 & 18.75 & 17.9 & $1,024.6$ & 1.05 \\
\hline 95 & 10 & 31.01 & 28 & 21.25 & 20.37 & 934.5 & 0.99 \\
\hline 90 & 6 & 26 & 25.47 & 16 & 15.53 & $1,098.7$ & 1.15 \\
\hline 90 & 12 & 27.83 & 29.74 & 20.42 & 20.95 & $1,197.2$ & 1.17 \\
\hline
\end{tabular}

TABLE 3. CENTRAL COMPOSITE DESIGN WITH EXPERIMENTAL AND PREDICTED VALUES OF TOTAL PHENOL CONTENT, TOTAL FLAVONOID CONTENT AND DPPH

of fit of the model was examined by $F$-test and the determination coefficient $R^{2}$. The greater the $F$ value is from unity, the more certain it is that the factors explain adequately the variation in the data around its mean, and the estimated factor effects are real. The ANOVA (Table 5) showed that this regression model was highly significant $(P<0.01)$, as is evident from the Fisher, $F$-test ( $F_{\text {model }}$, the ratio of mean square regression to mean square residual is 4.18), and has a low probability value $\left(\left[P_{\text {model }}>F\right]=0.0445\right)$. The value of 0.0521 for lack of fit implies that it is not significant as compared with the pure error, and that the model equation was adequate for predicting the TPC. The fitness of the model was further con-

\begin{tabular}{|c|c|c|c|c|c|c|c|c|c|}
\hline & \multicolumn{3}{|c|}{ Total phenol content } & \multicolumn{3}{|c|}{ Total flavonoid content } & \multicolumn{3}{|l|}{ DPPH } \\
\hline & Estimate & $S E^{*}$ & $P$ value & Estimate & $S E^{*}$ & $P$ value & Estimate & $S E^{*}$ & $P$ value \\
\hline Intercept & 25.47 & 0.95 & - & 15.53 & & & 1.15 & 0.032 & \\
\hline At & 0.53 & 0.75 & 0.5063 & -0.045 & -0.17 & 0.8724 & -0.039 & 0.026 & 0.1685 \\
\hline$B \neq$ & -1.27 & 0.75 & 0.1338 & 0.088 & 0.33 & 0.7546 & 0.084 & 0.026 & 0.0136 \\
\hline$A^{2}$ & -0.81 & 0.8 & 0.349 & 1.00 & 3.44 & 0.0109 & -0.038 & 0.027 & 0.21 \\
\hline$B^{2}$ & 3.04 & 0.8 & 0.0069 & 2.64 & 9.07 & $<0.0001$ & -0.048 & 0.027 & 0.1244 \\
\hline$A B$ & 1.05 & 1.06 & 0.355 & 1.15 & 2.08 & 0.0204 & -0.11 & 0.036 & 0.0195 \\
\hline
\end{tabular}

TABLE 4. COEFFICIENT ESTIMATE, STANDARD ERROR AND $P$ VALUES FOR TOTAL PHENOL CONTENT, TOTAL FLAVONOID CONTENT AND $\mathrm{DPPH}$

SE: standard error.

† A: temperature.

$\neq \mathrm{B}$ : time.

DPPH, 2,2-diphenyl-1-picrylhydrazyl.

TABLE 5. ANALYSIS OF VARIANCE AND REGRESSION ANALYSIS FOR TOTAL PHENOL CONTENT, TOTAL FLAVONOID CONTENT AND DPPH

\begin{tabular}{|c|c|c|c|c|c|c|c|c|c|c|c|c|c|c|c|}
\hline \multirow[b]{2}{*}{ Source } & \multicolumn{5}{|c|}{ Total phenol content } & \multicolumn{5}{|c|}{ Total flavonoid content } & \multicolumn{5}{|l|}{ DPPH } \\
\hline & $\mathrm{SS}^{\mathrm{a}}$ & $\mathrm{DF}^{\mathrm{b}}$ & $\mathrm{MSc}^{\mathrm{c}}$ & Fvalue & Prob $>F$ & $\mathrm{SS}^{\mathrm{a}}$ & $\mathrm{DF}^{\mathrm{b}}$ & $\mathrm{MSc}^{\mathrm{c}}$ & Fvalue & Prob $>F$ & $\mathrm{SS}^{\mathrm{a}}$ & $\mathrm{DF}^{\mathrm{b}}$ & $\mathrm{MSc}^{\mathrm{c}}$ & Fvalue & Prob $>F$ \\
\hline Model & 93.89 & 5 & 18.78 & 4.18 & 0.0445 & 57.06 & 5 & 11.41 & 19.31 & 0.0006 & 0.14 & 5 & 0.028 & 5.31 & 0.0247 \\
\hline Residual & 31.48 & 7 & 4.5 & & & 4.14 & 7 & 0.59 & & & 0.036 & 7 & 0.005 & & \\
\hline Lack of fit & 26.07 & 3 & 8.69 & 6.43 & 0.0521 & 3.09 & 3 & 1.03 & 3.91 & 0.1103 & 0.022 & 3 & 0.007 & 2 & 0.257 \\
\hline Pure error & 5.41 & 4 & 1.35 & & & 1.05 & 4 & 0.26 & & & 0.015 & 4 & 0.003 & & \\
\hline Total & 125.37 & 12 & & & & 61.20 & 12 & & & & 0.17 & 12 & & & \\
\hline
\end{tabular}

\footnotetext{
a Sum of squares.

b Degrees of freedom.

c Mean square.

DPPH, 2,2-diphenyl-1-picrylhydrazyl.
} 


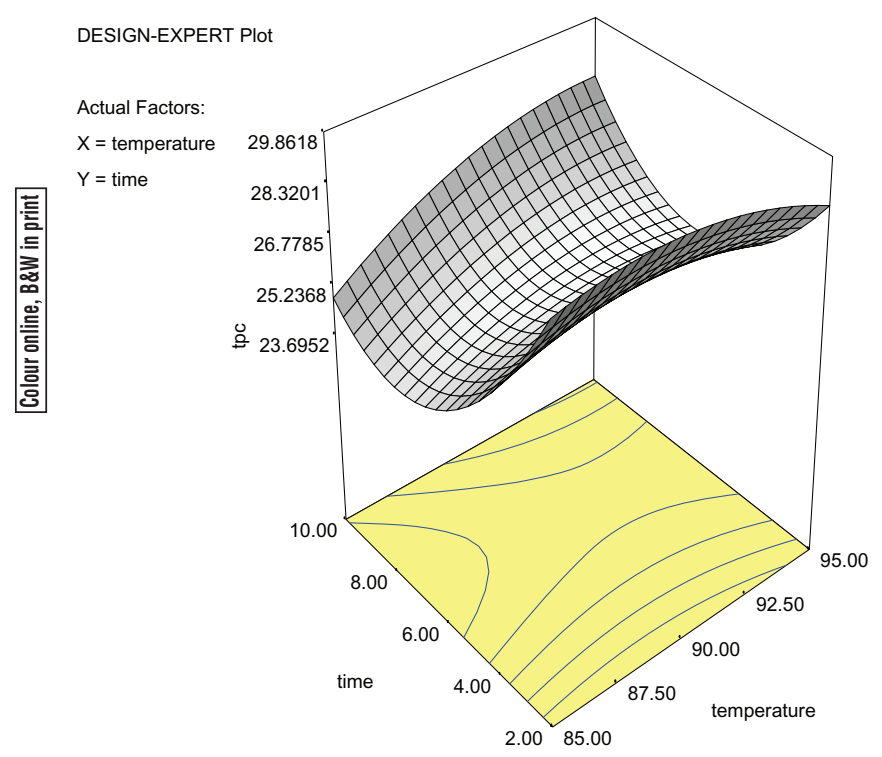

FIG. 1. SURFACE PLOT OF THE TOTAL PHENOLIC COMPOUNDS AS A FUNCTION OF BLANCHING TIME AND TEMPERATURE

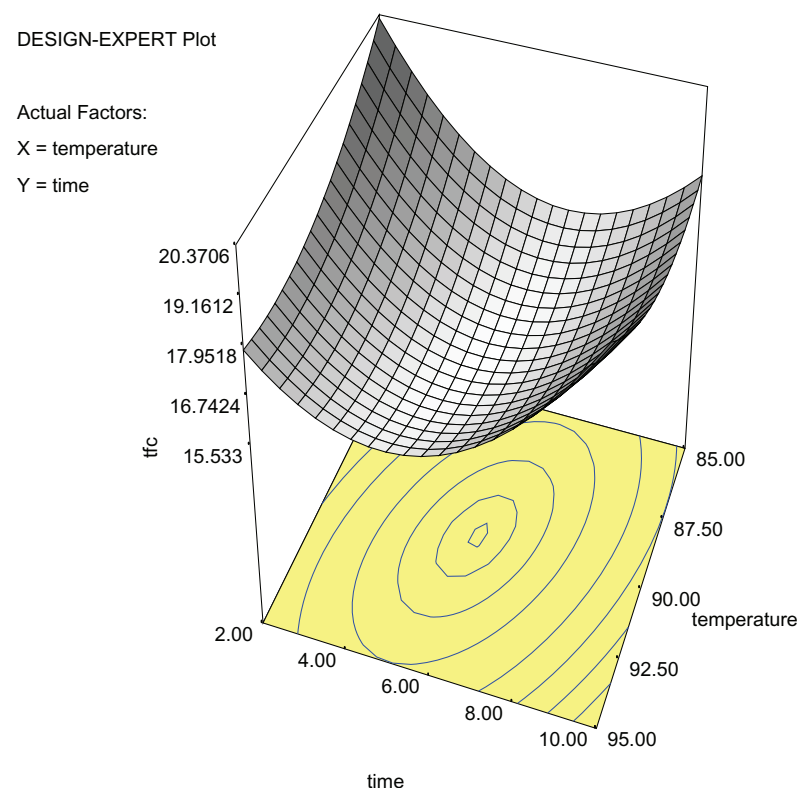

time

FIG. 2. SURFACE PLOT OF THE TOTAL FLAVONOID COMPOUNDS AS A FUNCTION OF BLANCHING TIME AND TEMPERATURE

$$
\begin{aligned}
\text { TFC }= & +15.53-0.045 X_{1}+0.088 X_{2}+1.00 X_{1}^{2} \\
& +2.64 X_{2}^{2}+1.15 X_{1} X_{2}
\end{aligned}
$$

When the values of $X_{1}-X_{2}$ were substituted in the above equation, the predicted TFC $(Y)$ was obtained. A comparison of predicted and experimentally obtained values can be seen in Table 3 . The corresponding $P$ values suggest that among the test variables used in this study, $\left(X_{1}\right)^{2}$ (temperature $\times$ temperature), $\left(X_{2}\right)^{2} \quad$ (time $\times$ time $)$ and $\left(X_{1} \times X_{2}\right)$ (temperature $\times$ time) are the significant model terms with $P$ values of less than 0.05 (Table 4$)$. The ANOVA (Table 5) showed that this regression model was highly significant $(P<0.01)$, as is evident from the Fisher, $F$-test $\left(F_{\text {model }}\right.$ is 19.33$)$, and has a low probability value $\left(\left[P_{\text {model }}>F\right]=\right.$ $0.0006)$. The value of 0.1103 for lack of fit implies that it is not significant in comparison with the pure error, and that the model equation was adequate for predicting the TFC. The fitness of the model was further confirmed by a satisfactory value of determination coefficient, which was calculated to be 0.9324 , indicating that $93.24 \%$ of the variability in the response could be predicted by the model. Furthermore, the predicted and experimental TFC values are given in Table 3. The agreement between the TFC predicted by the model and the experimental data is very strong, as shown by a high value of correlation coefficient, $R(0.9658)$.

As shown in Fig. 2, the symmetrical sunken shape contour with the maximum response at the central contour indicates that there was a significant interaction between temperature and time for TFC. The response surface of TFC gradually
Effect of Process Variables on TFC. Experimental results for TFC were fitted to a full quadratic second-order polynomial equation by applying multiple regression analysis (Eq. 5), and the regression coefficients obtained to predict the polynomial model for TFC are as follows: 


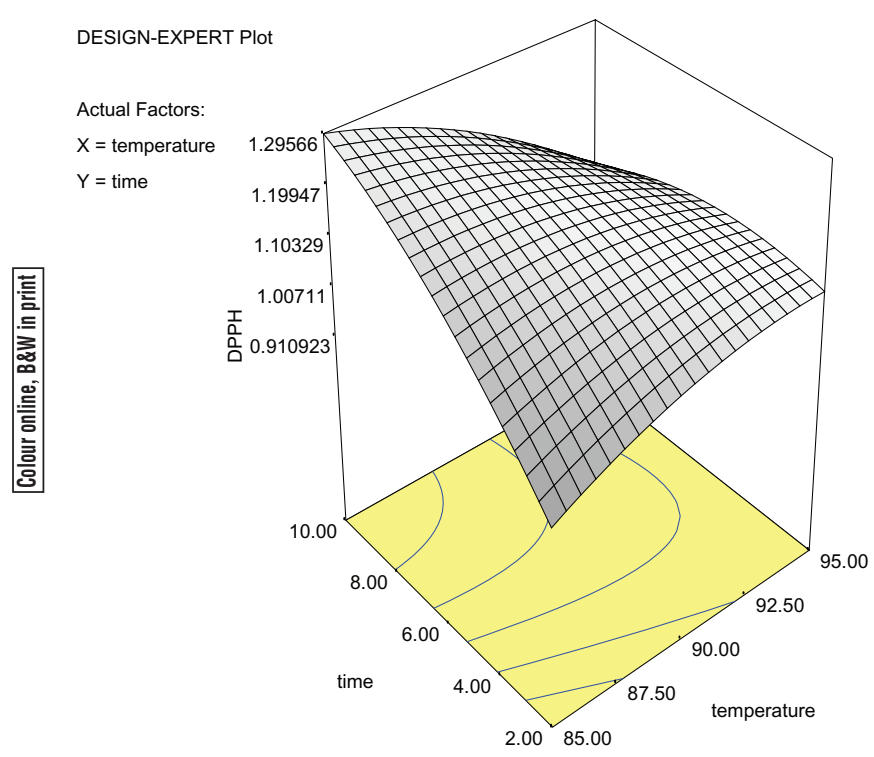

FIG. 3. SURFACE PLOT OF 2,2-DIPHENYL-1-PICRYLHYDRAZYL AS A FUNCTION OF BLANCHING TIME AND TEMPERATURE

decreased with increasing temperature from 85 up to $90 \mathrm{C}$ for any value of time and again gradually increased after 95C.

Effect of Process Variables on DPPH. A quadratic second-order polynomial equation was obtained for DPPH by applying multiple regression analysis (Eq. 6) and predicted the polynomial model for DPPH as follows:

$$
\begin{gathered}
D P P H=+1.15-0.039 X_{1}+0.084 X_{2}-0.038 X_{1}^{2} \\
-0.048 X_{2}^{2}-0.11 X_{1} X_{2}
\end{gathered}
$$

A comparison of predicted and experimentally obtained values can be seen in Table 3 . The corresponding $P$ values suggest that among the test variables used in this study, $\left(X_{2}\right)$ (time) and $\left(X_{1} \times X_{2}\right)$ (temperature $\times$ time $)$ are the significant model terms with $P$ values of less than 0.05 (Table 4 ). The ANOVA (Table 5) showed that this regression model was highly significant $(P<0.01)$, as is evident from the Fisher, F-test $\left(F_{\text {model }}\right.$ is 5.31 ), and has a low probability value $\left(\left[P_{\text {model }}>F\right]=0.0247\right)$. The value of 0.2570 for lack of fit was not significant compared with the pure error. The value of determination coefficient $(0.7914)$ was satisfactory along with a good value of correlation coefficient $(R=0.8896)$.

Figure 3 shows the effect of time and temperature on the DPPH levels. Time and temperature have inverse effects on the DPPH levels. The $\mathrm{EC}_{50}$ values were reduced as the temperature increased and as the time decreased. A lower value of $\mathrm{EC}_{50}$ (concentration of sample required to scavenge $50 \%$ free radical) indicates a higher antioxidant capacity. $\mathrm{EC}_{50}$ value is negatively related to the antioxidant activity as it expresses the amount of antioxidant required to reduce the radical concen-

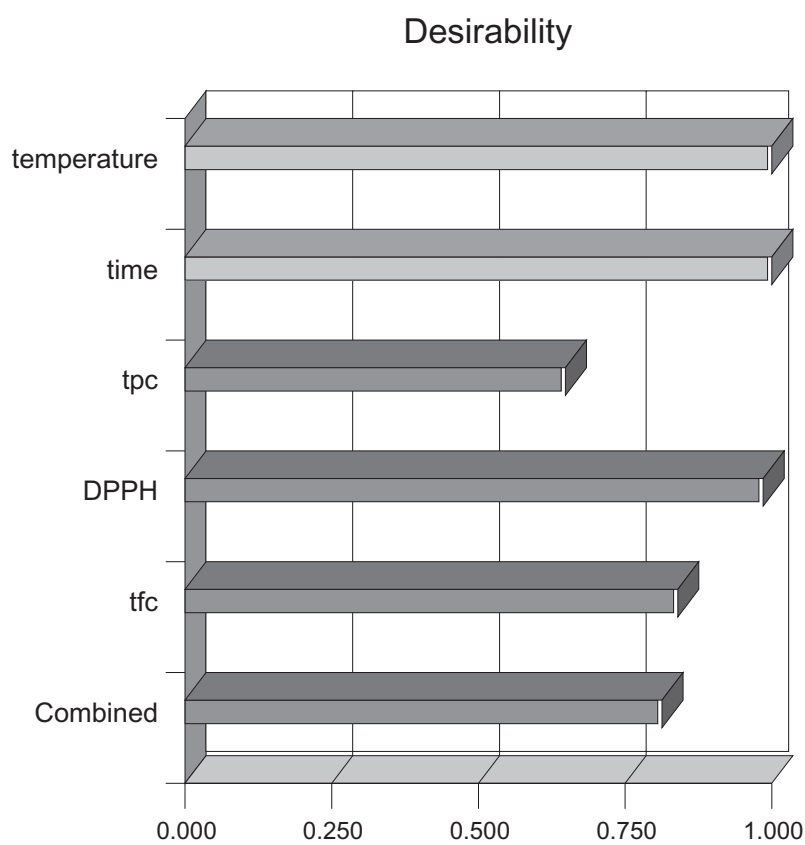

FIG. 4. BAR GRAPH REPRESENTING INDIVIDUAL DESIRABILITY OF ALL RESPONSES $\left(d_{i}\right)$ IN CORRESPONDENCE WITH COMBINED DESIRABILITY (d)

tration by $50 \%$. Thus, high temperature and shorter time seem to be favorable for a high antioxidant capacity. This could be the result of the formation of Maillard reaction products, which have been shown to have potent antioxidant activities (Turkmen et al. 2005). Similar to the trends obtained in the present study, Amin et al. (2006) also reported that the antioxidant activity of blanched spinach was reduced as the blanching time increased. Chu et al. (2000) reported that blanching for less than 1 min would retain the high antioxidant activity in the green leaves of sweet potatoes.

\section{Optimization of the Blanching Conditions}

The above experiments showed the effect of different blanching combinations of blanching time and temperature on the phytochemicals in cabbage. Thus, in order to achieve a combination wherein minimal loss of phytochemicals was occurring, optimization was carried out using Numerical option of the Design expert software. The values of responses were converted into a desirability function. The desirability values of the minimum and maximum yields were configured as 0 and 1 , respectively, and then all the other response yields could be converted into desirability values between 0 and 1 . The desired goal was selected by adjusting the weight or importance that might alter the characteristics of a goal. The goal fields for response have five options: none, maximum, minimum, target and within range. For each goal, the importance can be varied 


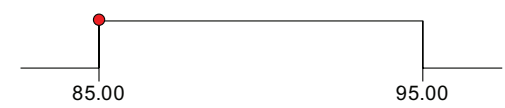

temperature $=85.00$

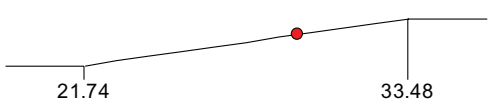

$\mathrm{tpc}=29.4949$

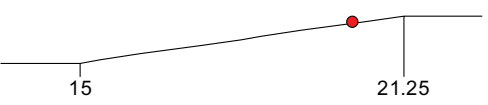

$\mathrm{tfc}=20.2844$

FIG. 5. DESIRABILITY RAMP FOR NUMERICAL OPTIMIZATION FOR DIFFERENT FACTORS AND RESPONSES

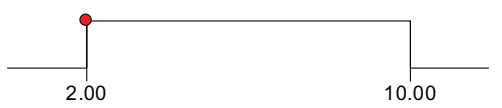

time $=2.00$

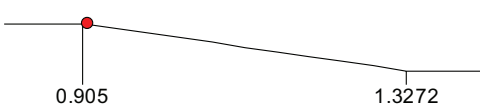

$\mathrm{DPPH}=0.910923$ from 1 (less importance) to 5 (maximum importance). As the aim was to achieve higher concentration of TPC and TFC, the goal was set to "maximize" with importance " 5 ." For DPPH, the goal was set to "minimize" as lesser DPPH value means higher antioxidant capability. The individual desirability function $\left(d_{i}\right)$ for each of the responses and the calculated geometric mean as maximum over all desirability $(D=0.82)$ are represented in Fig. 4. Applying the desirability function with all the preselected goals for each factor gave the specific value for all responses, which are presented in Fig. 5. The software optimized $29.5 \mathrm{mg} \mathrm{GAE} / \mathrm{gm}$ TPC, $20.3 \mathrm{mg} \mathrm{QE} / \mathrm{gm}$ TFC and EC 50 of $0.91 \mathrm{mg} / \mathrm{mL}$ with the optimized factors of 2 min blanching time at $85 \mathrm{C}$. Finally, for their validation, duplicate confirmatory experiments were conducted using the optimized parameters. The experimentally obtained values of TPC, TFC and DPPH were $31.01 \mathrm{mg} \mathrm{GAE} / \mathrm{gm}, 21.2 \mathrm{mg} \mathrm{QE} / \mathrm{g}$ and $0.93 \mathrm{mg} /$ $\mathrm{mL}$, respectively. The results are closely related to the data obtained from optimization analysis, resulting in a very good agreement. The difference between the experimental and model predicted values is less than $5 \%$ for all the three responses. This affirms that the models developed are precisely adequate for predicting the responses. Therefore, CCD along with the desirability functions could be effectively used to optimize the blanching time and temperature conditions for maximizing the phytochemical content in processed vegetables. The utilization of the software was very helpful in achieving a combination of temperature and time that could result in almost similar phytochemical content as compared with fresh cabbage (TPC: $33.5 \mathrm{mg}$ GAE/g; TFC = $21.6 \mathrm{mg} \mathrm{QE} / \mathrm{g}$; and DPPH: $0.827 \mathrm{mg} / \mathrm{mL})$.

\section{CONCLUSION}

The present study investigated the effect of two heat processing methods (microwaving and blanching) on the phy- tochemical content of York cabbage as a pretreatment method prior to its further utilization and applications. Microwaving was seen to have more deleterious effect on the phytochemicals as compared with blanching. Blanching time and temperature were optimized by RSM in order to achieve conditions that result in minimal loss in phytochemicals. An empirical model was developed to simulate TPC, TFC and $\mathrm{DPPH}$ in terms of blanching time and temperature (factors) by RSM, and an ANOVA test was performed, which showed a good fitting of the model. The application of RSM in optimization of blanching time and temperature helps in cutting down the amount time and resources for identifying optimum value of different factors and allows better understanding of the interaction between the variables.

\section{ACKNOWLEDGMENT}

The authors would like to acknowledge funding from the Irish Government under the Technological Sector Research Scheme (Strand III) of the National Development Plan.

\section{REFERENCES}

ABDEL-FATTAH, Y.R., SAEED, H.M., GOHAR, Y.M. and EL-BAZ, M.A. 2005. Improved production of Pseudomonas aeruginosa uricase by optimization of process parameters through statistical experimental designs. Proc. Biochem. 40, 1707-1714.

AMIN, I., NORAZAIDAH, Y. and EMMY HAINIDA, K.I. 2006. Antioxidant activity and phenolic content of raw and blanched Amaranthus species. Food Chem. 94, 47-52.

BREENA, W.M. 1994. Healthfulness and nutritional quality of fresh versus processed fruits and vegetables: A review. J. Foodserv. Syst. 8, 1-45. 
BROOKS, J.D., PATON, V.G. and VIDANES, G. 2001. Potent induction of phase 2 enzymes in human prostate cells by sulforaphane. Cancer Epidemiol. Biomarkers Prev. 10, 949-954.

CERRETANI, L., BENDINI, A., RODRIGUEZ-ESTRADA, M.T., VITTADINI, E. and CHIAVARO, E. 2009. Microwave heating of different commercial categories of olive oil: Part I. Effect on chemical oxidative stability indices and phenolic compounds. Food Chem. 115, 1381-1388.

CHU, Y.H., CHANG, C.L. and HSU, H.F. 2000. Flavonoid content of several vegetables and their antioxidant activity. J. Sci. Food Agric. 80, 561-566.

DUH, P.D., YEN, G.C., YEN, W.J. and CHANG, L.W. 2001. Antioxidant effects of water extracts from Barley (Hordeum vulgare L.) prepared under different roasting temperatures. J. Agric. Food Chem. 49, 1455-1463.

FRANKE, A.A., CUSTER, L.J., ARAKAKI, C. and MURPHY, F.P. 2004. Vitamin C and flavonoid levels of fruits and vegetables consumed in Hawaii. J. Food Compost. Anal. 17, 1-35.

GAWLIK-DZIKI, U. 2008. Effect of hydrothermal treatment on the antioxidant properties of broccoli (Brassica oleracea var. botrytis italica) florets. Food Chem. 109, 393-401.

HOLLMAN, P.C.H. 2001. Evidence for health benefits of plant phenols: Local or systemic effects? J. Sci. Food Agric. 81, 842-852.

ISMAIL, A., MARJAN, Z.M. and FOONG, C.W. 2004. Total antioxidant activity and phenolic content in selected vegetables. Food Chem. 87, 581-586.

KUSZNIEREWICZ, B., BARTOSZEK, A., WOLSKA, L., DRZEWIECKI, J., GORINSTEIN, S. and NAMIESNIK, J. 2008. Partial characterization of white cabbages (Brassica oleracea var. capitata f. alba) from different regions by glucosinolates, bioactive compounds, total antioxidant activities and proteins. LWT - Food Sci. Technol. 41, 1-9.

LINDLEY, M.G. 1998. The impact of food processing on antioxidants in vegetable oils, fruits and vegetables. Trends Food Sci. Technol. 9, 336-340.

LIU, S.C., LIN, J.T., WANG, C.K., CHEN, H.Y. and YANG, D.J. 2009. Antioxidant properties of various solvent extracts from lychee (Litchi chinenesis Sonn.) flowers. Food Chem. 114, 577-581.

LIU, J., LUO, J., YE, H., SUN, Y., LU, Z. and ZENG, X. 2010. Medium optimization and structural characterization of exopolysaccharides from endophytic bacterium Paenibacillus polymyxa EJS-3. Carbohydr. Polym. 79, 206-213.

LOMBARD, K., PEFFLEY, E., GEOFFRIAU, E., THOMPSON, L. and HERRING, A. 2005. Quercetin in onion (Allium cepa L.) after heat-treatment simulating home preparation. J. Food Compost. Anal. 18, 571-581.

MURTHY, M.S.R., SWAMINATHAN, T., RAKSHIT, S.K. and KOSUGI, Y. 2000. Statistical optimization of lipase catalyzed hydrolysis of methyloleate by response surface methodology. Bioprocess Eng. 22, 35-39.

PUUPPONEN-PIMIÄ, R., HÄKKINEN, S.T., AARNI, M., SUORTTI, T., LAMPI, A.M., EUROLA, M., PIIRONEN, V.,
NUUTILA, A.M. and OKSMAN-CALDENTEY, K.M. 2003. Blanching and long-term freezing affect various bioactive compounds of vegetables in different ways. J. Sci. Food Agric. 83, 1389-1402.

ROY, M.K., JUNEJA, L.R., ISOBE, S. and TSUSHIDA, T. 2009. Steam processed broccoli (Brassica oleracea) has higher antioxidant activity in chemical and cellular assay systems. Food Chem. 114, 263-269.

RUNGAPAMESTRY, V., DUNCAN, A.J., FULLER, Z. and RATCLIFFE, B. 2006. Changes in glucosinolate concentrations, myrosinase activity, and production of metabolites of glucosinolates in cabbage (Brassica oleracea var. capitata) cooked for different durations. J. Agric. Food Chem. 54, 7628-7634.

SROKA, Z. and CISOWSKI, W. 2003. Hydrogen peroxide scavenging antioxidant and anti-radical activity of some phenolic acids. Food Chem. Toxicol. 41, 753-758.

SULTANA, B., ANWAR, F. and IQBAL, S. 2008. Effect of different cooking methods on the antioxidant activity of some vegetables from Pakistan. Int. J. Food Sci. Technol. 43, 560-567.

TAGA, M.S., MILLER, E.E. and PRATT, D.E. 1984. Chia seeds as a source of natural lipid antioxidants. J. Am. Oil Chem. Soc. 61, 928-931.

TAVEIRA, M., PEREIRA, D.M., SOUSA, C., FERRERES, F., ANDRADE, P.B., MARTINS, A., PEREIRA, J.A. and VALENTAัO, P. 2009. In vitro cultures of Brassica oleracea L. var. costata DC: Potential plant bioreactor for antioxidant phenolic compounds. J. Agric. Food Chem. 57, 1247-1252.

TURKMEN, N., SARI, F. and VELIOGLU, Y.S. 2005. The effect of cooking methods on total phenolics and antioxidant activity of selected green vegetables. Food Chem. 93, 713-718.

VOLDEN, J., BORGE, G.I.A., BENGTSSON, G.B., HANSEN, M., THYGESEN, I.E. and WICKLUND, T. 2008. Effect of thermal treatment on glucosinolates and antioxidant-related parameters in red cabbage (Brassica oleracea L. ssp. capitata f. rubra). Food Chem. 109, 595-605.

VOLDEN, J., BENGTSSON, G.B. and WICKLUND, T. 2009a. Glucosinolates, L-ascorbic acid, total phenols, anthocyanins, antioxidant capacities and colour in cauliflower (Brassica oleracea L. ssp. botrytis); effects of long-term freezer storage. Food Chem. 112, 967-976.

VOLDEN, J., BORGE, G.I.A., HANSEN, M., WICKLUND, T. and BENGTSSO, G.B. 2009b. Processing (blanching, boiling, steaming) effects on the content of glucosinolates and antioxidant-related parameters in cauliflower (Brassica oleracea L. ssp. botrytis). LWT - Food Sci. Technol. 42, 63-73.

Food and Agriculture Organization of the United Nations 2011. http://faostat.fao.org/site/339/default.aspx (accessed January $15,2011)$.

XU, B. and CHANG, S.K.C. 2008. Effect of soaking, boiling, and steaming on total phenolic content and antioxidant activities of cool season food legumes. Food Chem. 110, 1-13.

YEN, G.C. and CHEN, H.Y. 1995. Antioxidant activity of various tea extracts in relation to their antimutagenecity. J. Agric. Food Chem. 43, 27-37. 
YU, L., LEI, T., REN, X., PEI, X. and FENG, Y. 2008. Response surface optimization of l-(+)-lactic acid production using corn steep liquor as an alternative nitrogen source by Lactobacillus rhamnosus CGMCC 1466. Biochem. Eng. J. 39, 496-502.
ZHANG, D.L. and HAMAUZU, Y. 2004. Phenolics, ascorbic acid, carotenoids and antioxidant activity of broccoli and their changes during conventional and microwave cooking. Food Chem. 88, 503-509. 